\title{
KUALITAS LAPORAN VISUM et REPERTUM KASUS PERLUKAAN KORBAN HIDUP DI RUMAH SAKIT BHAYANGKARA PALU TAHUN 2017
}

\author{
Safirah Furqani ${ }^{1}$, Annisa S Muthaher ${ }^{1}$, Nasrun ${ }^{1 *}$ \\ ${ }^{1}$ Program Studi Pendidikan Dokter, Fakultas Kedokteran Universitas Alkhairat, Jl. Diponegoro No. 39 \\ Palu 94221, Sulawesi Tengah, Indonesia
}

*Corresponding author: Telp: +6287841111100 email: n4sroen@ yahoo.com

\begin{abstract}
ABSTRAK
Visum et Repertum dapat dikatakan baik apabila mampu membuat terang perkara tindak pidana yang terjadi dengan melibatkan bukti-bukti forensik yang cukup, hal tersebut dikarenakan Visum et Repertum merupakan laporan tertulis yang dibuat oleh dokter mencakup apa yang diperiksanya dan interpretasinya sesuai keilmuannya terhadap manusia baik hidup atau mati atas permintaan tertulis dari penyidik berdasarkan sumpah dalam perkara pidana serta bertujuan untuk kepentingan peradilan.Pada penelitian yang dilakukan untuk mendapatkan gambaran kualitas Visum et Repertum terhadap 92 laporan Visum et Repertum kasus perlukaan korban hidup di RS Bhayangkara kota Palu pada tahun 2017, dengan metode desain penelitian deskriptif retrospektif cross sectional, didapatkan bahwa kualitas Visum et Repertum perlukaan korban hidup di RS.Bhayangkara kota Palu tahun 2017 adalah sebagai berikut (1) laporan bagian pendahuluan mendapatkan nilai $60,95 \%$ dikategorikan berkualitas sedang.(2) laporan pemberitaan mendapatkan nilai $75,81 \%$ dikategorikan berkualitas baik.(3) laporan bagian kesimpulan mendapatkan nilai 50,54\% dikategorikan berkualitas sedang (4) laporan Visum et Repertum perlukaan korban hidup mendapatkan nilai 60,95\% dikategorikan berkualitas sedang,sehingga dapat disimpulkan bahwa Visum et Repertum perlukaan pada korban hidup pada RS.Bayangkara kota Palu tahun 2017 secara keseluruhan adalah berkualitas sedang dengan nilai $60,95 \%$.
\end{abstract}

Kata Kunci: Visum et Repertum, tindak pidana, Rumah Sakit Bhayangkara

\section{ABSTRACT}

Visum et Repertum is good if it is able to clear of criminal cases that occur by involving sufficient forensic evidence, it is because Visum et Repertum is a written report made by the doctor covering what he examined and its interpretation according to his knowledge. human beings either live or die at the written request of the investigator based on oath in criminal cases and aimed at the benefit of the judiciary. In the study conducted to get an overview of the quality of Visum et Repertum on 92 reports visum et repertum cases of the need for victims living in Bhayangkara Hospital in 2017, With descriptive research design methods retrospective cross sectional, it was obtained that the quality of Visum et Repertum needs victims living in hospital. Bhayangkara in 2017 is as follows (1) preliminary report getting a value of $60.95 \%$ categorized as medium quality. (2) news reports get a value of $75.81 \%$ categorized as good quality. (3) the report of the conclusion section gets a value of $50.54 \%$ categorized as moderate quality (4) visum et repertum report needs to live victims get a value of $60.95 \%$ categorized as moderate quality, so it can be concluded that Visum et Repertum needs to be in the victims living in hospital. Bayangkara Palu City in 2017 as a whole is of medium quality with a value of 60.95\%.

Keywords : Visum et Repertum, criminal cases, Bhayangkara Hospital

\section{PENDAHULUAN}

Visum et repertum (VeR) berasal dari kata visual yaitu melihat dan repertum yang memiliki arti melaporkan. Visum et Repertum merupakan laporan tertulis yang dibuat oleh dokter mencakup apa yang diperiksanya dan interpretasinya sesuai keilmuannya terhadap manusia baik hidup atau mati atas permintaan 
tertulis dari penyidik berdasarkan sumpah dalam perkara pidana serta bertujuan untuk peradilan. ${ }^{1,2,3}$

Visum et Repertum (VeR) berkedudukan sebagai alat bukti sah berdasarkan yang tertuang dalam pasal 184 KUHAP. $^{3}$ VeR memiliki andil dalam pembuktian suatu perkara pidana atas kesehatan dan jiwa manusia dengan mengungkapkan hasil pemeriksaan medis pada bagian pemberitaan sebagai pengganti barang bukti serta berisi tentang pendapat dokter pada bagian kesimpulan. Sehingga seorang dokter dituntut untuk dapat membuat Visum et Repertum yang baik karena dibuat untuk keperluan hukum dan peradilan. $^{1,3}$

Visum et Repertum dapat dikatakan baik apabila mampu membuat terang perkara tindak pidana yang terjadi dengan melibatkan buktibukti forensik yang cukup. Penilaian kualitas Visum et Repertum berdasarkan metode skoring herkutanto adalah dengan melihat kelengkapan variabel yang tertulis dalam Visum et Repertum. Dikatakan berkualitas baik bila skor > 75\%, kualitas sedang 75\%-50\% dan kualitas buruk $<50 \%$. ${ }^{4,5}$

Data resmi mengenai kualitas Visum et Repertum di indonesia belum ada, namun menurut beberapa hasil penelitian dari kualitas Visum et Repertum masih banyak yang berkualitas buruk. Berdasarkan penelitian Herkutanto diperoleh hasil yang rendah dari 34 rumah sakit di jakarta hanya $15,4 \%$ berkualitas baik. Penelitian yang dilakukan oleh Soularto, DS pada RS. PKU Muhammadiyah Yogyakarta tentang kualitas Visum et Repertum korban kekerasan seksual didapatkan hasil skor 27,4\% berarti kualitas VeR buruk. Selain itu pada Kuantan singingi, Bengkalis, Siapi-api, Pekanbaru, Dumai, dan Indragiri Hulu juga didapatkan Visum et Repertum berkualitas buruk dengan hasil skoring kurang dari 50\%. Pada kepulauan meranti didapatkan hasil skor $50 \%$ yaitu berkualitas sedang, dimana hasil penelitian di mandau dan siak juga didapatkan berkualitas sedang, yaitu hasil skoring di mandau sebesar $72,64 \%$ dan di siak 52,97\%.

\section{METODOLOGI}

Desain penelitian yang digunakan adalah deskriptif retrospektif yaitu dengan melakukan observasi hingga mendeskripsikan kualitas Visum et Repertum berdasarkan tiga kualifikasi pembagian yaitu berdasarkan 1) kualitas bagian pendahuluan; 2)kualitas bagian pemberitaan; 3)kualitas bagian kesimpulan, terhadap data sekunder Visum et Repertum perlukaan di Rumah Sakit Bhayangkara kota Palu periode Januari-Desember 2017, yang kemudian hasilnya dinilai berdasarkan kriteria objektif metode skoring Herkutanto yaitu :

Kualitas baik $\quad=>75 \%$

Kualitas sedang $\quad=50 \%-75 \%$

Kualitas buruk $\quad=<50 \%$

Nilai kualitas bagian kesimpulan:

(rata-rata skor total $\times 8 / 16) \times 100 \%$

\section{HASIL DAN PEMBAHASAN}

\section{HASIL}

Sejumlah 92 sampel Visum et Repertum perlukaan korban hidup yang telah memenuhi kriteria inklusi. Dari penelitian yang dilakukan pada bulan april 2018 hingga bulan juni 2018, menggunakan checklist data yang diperoleh adalah pada bagian pemberitahuan yaitu tempat pemeriksaan, waktu pemeriksaan, data subjek, data peminta, dan data pemeriksa. Pada bagian pemberitaan yaitu anamnesis, tanda vital, lokasi luka, karakteristik luka, ukuran luka, pengobatan dan perawatan. Kemudian pada bagian kesimpulan yaitu jenis luka dan jenis kekerasan, dan kualifikasi luka. Hasil analisa statistik ditampilkan dengan sistematika sebagai berikut:

\section{Kualitas laporan Visum et Repertum bagian pendahuluan.}

Tabel 1. Kualitas laporan VeR perlukaan korban hidup bagian pendahuluan pada RS.Bhayangkara kota Palu tahun 2017

\begin{tabular}{|c|c|c|}
\hline Struktur VeR & Unsur yang dinilai & $\begin{array}{l}\text { Rerata } \\
\text { skor }\end{array}$ \\
\hline $\begin{array}{l}\text { Bagian } \\
\text { pendahuluan }\end{array}$ & $\begin{array}{l}\text { Tempat pemeriksaan } \\
\text { Waktu pemeriksaan } \\
\text { Data subyek } \\
\text { Data peminta } \\
\text { pemeriksaan } \\
\text { Data pemeriksa }\end{array}$ & $\begin{array}{l}1,00 \\
1,00 \\
2,00 \\
1,00 \\
2,00\end{array}$ \\
\hline $\begin{array}{l}\text { Rerata skor } \\
\text { total }\end{array}$ & & 1,40 \\
\hline
\end{tabular}

$(1,40 \times 1 / 2) \times 100 \%=60,95 \%$ 
Dari data diatas didapatkan kualitas laporan Visum et Repertum perlukaan korban hidup bagian pendahuluan pada RS.Bhayangkara kota Palu mendapatkan nilai $60,95 \%$ yang dikategorikan berkualitas sedang.

\section{Kualitas laporan Visum et Repertum bagian pemberitaan}

Tabel 2. Kualitas laporan VeR perlukaan korban hidup bagian pemberitaan pada RS.Bhayangkara kota Palu tahun 2017

\begin{tabular}{|c|c|c|}
\hline Struktur VeR & Unsur yang dinilai & $\begin{array}{l}\text { Rerata } \\
\text { skor }\end{array}$ \\
\hline \multirow{6}{*}{$\begin{array}{l}\text { Bagian } \\
\text { pemberitaan }\end{array}$} & Anamnesis & 1,16 \\
\hline & Tanda vital & 2,00 \\
\hline & Lokasi luka & 1,98 \\
\hline & Karakteristik luka & 1,83 \\
\hline & Ukuran luka & 1,97 \\
\hline & $\begin{array}{l}\text { Pengobatan dan } \\
\text { perawatan }\end{array}$ & 0,01 \\
\hline $\begin{array}{l}\text { Rerata skor } \\
\text { total }\end{array}$ & & 1,49 \\
\hline
\end{tabular}

$(1,49 \times 5 / 10) \times 100 \%=74,81 \%$

Dari data diatas didapatkan kualitas laporan Visum et Repertum perlukaan korban hidup bagian pemberitaan pada RS.Bhayangkara kota Palu mendapatkan nilai $74,81 \%$ yang dikategorikan berkualitas sedang.

\section{Kualitas laporan Visum et Repertum} bagian kesimpulan

Tabel 3. Kualitas laporan VeR perlukaan korban hidup bagian kesimpulan pada RS.Bhayangkara kota Palu tahun 2017

\begin{tabular}{lll}
\hline Struktur VeR & Unsur yang dinilai & $\begin{array}{l}\text { Rerata } \\
\text { skor }\end{array}$ \\
\hline $\begin{array}{l}\text { Bagian } \\
\text { kesimpulan }\end{array}$ & $\begin{array}{l}\text { Jenis luka dan jenis } \\
\text { kekerasan } \\
\text { Kualifikasi luka }\end{array}$ & $\begin{array}{l}1,95 \\
0,06\end{array}$ \\
\hline Rerata skor total & 1,01 \\
\hline$(1,01 \times 8 / 16) \times 100 \%=50,54 \%$ & \\
\multicolumn{2}{l}{. } &
\end{tabular}
laporan Visum et Repertum perlukaan korban hidup bagian kesimpulan pada RS.Bhayangkara kota Palu mendapatkan nilai $50,54 \%$ yang dikategorikan berkualitas sedang.
Dari ketiga kategori tersebut kemudian dinilai kualitas keseluruhan dari hasil yang telah didapatkan.

\section{4. kualitas laporan Visum et repertum perlukaan korban hidup}

Tabel 4. Kualitas laporan VeR perlukaan korban hidup pada RS.Bhayangkara kota Palu tahun 2017

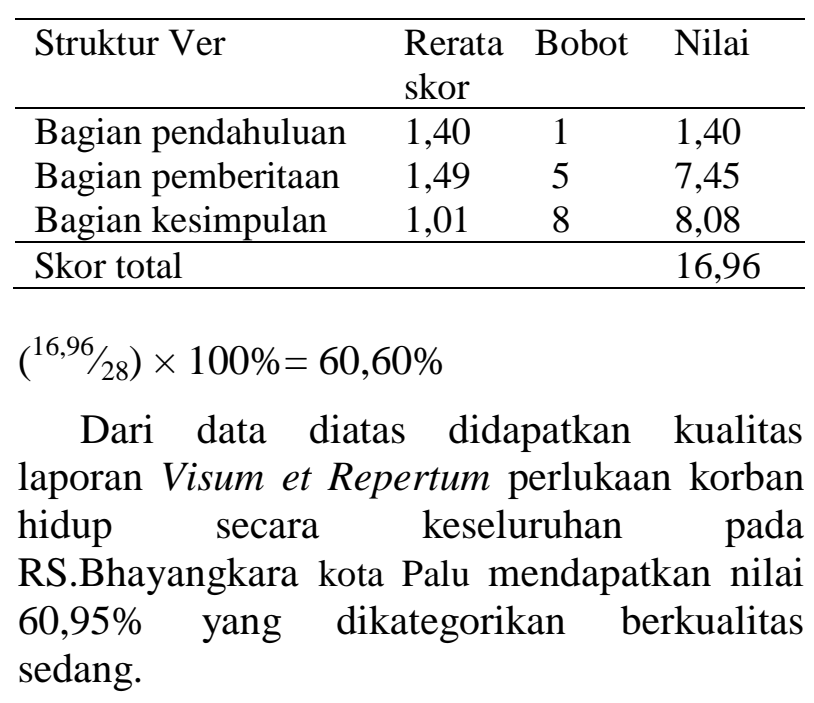

\section{PEMBAHASAN}

\section{Kualitas Visum et Repertum bagian pendahuluan}

Berdasarkan penelitian terhadap data laporan VeR perlukaan korban hidup bagian pendahuluan pada RS.Bhayangkara kota Palu tahun 2017 didapatkan nilai 60,95\% yaitu dikategorikan berkualitas sedang. Hasil penelitian yang sama ditemukan pada penelitian Pratiwi,WS yang dilakukan pada RSUD kuantan singingi yang memperlihatkan kualitas sedang dengan nilai $72,3 \% .{ }^{10}$ Hasil serupa juga didapatkan pada penelitian Lestari, RA dan Ramadhan FT dengan masing-masing nilai $69,34 \%$ dan $71 \% .^{11,13}$ Walaupun hasil yang didapatkan pada RS. Bhayangkara kota Palu sama-sama berkualitas sedang namun hasil nilai yang didapatkan masih lebih relatif rendah dibandingkan tiga penelitian sebelumnya.

Pada bagian ini dokter telah menuliskan dua variabel visum secara lengkap yaitu data subyek dan data pemeriksa. Namun untuk tiga variabel lainnya yaitu tempat pemeriksaan, waktu pemeriksaan dan data peminta 
pemeriksaan masih kurang lengkap. Pada tempat pemeriksaan dari 92 sampel semuanya mendapat skor 1 hal ini dikarenakan dokter hanya mencantumkan nama rumah sakit tanpa menuliskan bagian atau instalasi secara lengkap. Kemudian pada waktu pemeriksaan dokter tidak ada satupun yang mencantumkan jam pemeriksaan. Untuk data peminta pemeriksaan dokter hanya mencantumkan unit atau satuan kerja penyidik tanpa menulis serta nama penyidik yang meminta pembuatan Visum et Repertum.

\section{Kualitas laporan Visum et Repertum bagian pemberitaan}

Berdasarkan penelitian terhadap data laporan VeR perlukaan korban hidup bagian pemberitaan pada RS.Bhayangkara kota Palu tahun 2017 didapatkan nilai 74,81\% yaitu dikategorikan berkualitas sedang. Hasil penelitian ini sama dengan yang dilakukan oleh Kubri A , Lestari RA, Ramadhan FT, dimana hasil yang didapatkan berkualitas sedang dengan nilai secara berurutan $58,69 \%$ $, 55,09 \%$, dan $51,56 \%$. $^{9,11,13}$

Pada bagian pemberitaan hanya variabel tanda vital yang dituliskan secara lengkap. Pada variabel anamnesis dari 92 sampel hanya 15 sampel visum yang menuliskan anamnesis secara lengkap. Hal ini dikarenakan dokter kebanyakan hanya menuliskan biomekanika trauma dan tidak menuliskan keluhan korban saat diperiksa.Kemudian pada bagian pengobatan dan perawatan dari 92 sampel hanya 1 sampel VeR yang menuliskan pengobatan dan perawatan itupun tidak dituliskan secara lengkap.Hal ini mungkin disebabkan masih ada anggapan bahwa anamnesis dan pengobatan serta perawatan tidak penting dituliskan dalam $\mathrm{VeR}$ atau juga dapat disebabkan dokter pembuat VeR tidak mengetahui bahwa variabel tersebut harus dicantumkan ${ }^{6}$

\section{Kualitas laporan Visum et Repertum bagian kesimpulan}

Berdasarkan penelitian terhadap data laporan $\mathrm{VeR}$ perlukaan korban hidup bagian kesimpulan pada RS.Bhayangkara kota Palu tahun 2017 didapatkan nilai 50,54\% yaitu dikategorikan berkualitas sedang. Hasil penelitian ini sama dengan penelitian yang dilakukan oleh simangunsong IR pada RSUD Siak periode 1 januari 2009-31 desember 2013 dimana didapatkan kualitas Visum et Repertum berkualitas sedang dengan nilai $53 \% .^{8}$ Sehingga hasil penelitian Kualitas VeR perlukaan pada RS.Bhayangkara kota Palu tahun 2017 masih relatif lebih rendah.

Berdasarkan pengamatan peneliti dari kedua variabel dari bagian kesimpulan yaitu jenis luka dan jenis kekerasan serta kualifikasi luka masih belum lengkap. Pada bagian kesimpulan ini didapatkan hasil nilai yang terendah diantara bagian VeR yang lain. Pada bagian kualifikasi luka dari 92 sampel hanya 3 sampel VeR perlukaan yang dituliskan kualifikasi luka sesuai dengan rumusan pasal 351, 352, dan 90 KUHP. Rumusan ketiga pasal ini membedakan kualifikasi luka menjadi luka ringan, sedang, dan berat sehingga dalam segi hukum konsekuensi hukuman yang didapatkan juga berbeda bagi pelakunya., ${ }^{1,6}$ Sehingga bisa dikatakan bahwa kualifikasi luka merupakan hal penting bagi hakim dalam menentukan derajat hukuman pelaku tindak pidana. ${ }^{6}$ Kualifikasi luka merupakan hasil interpretasi dokter dari apa yang ditemukan pada tubuh pasien, hal ini seharusnya menjadi perhatian khusus karena kekeliruan penyimpulan luka secara benar dapat menimbulkan ketidakadilan bagi pelaku maupun korban.,

\section{Kualitas laporan Visum et repertum perlukaan korban hidup}

Berdasarkan penelitian terhadap data laporan VeR perlukaan korban hidup secara keseluruhan pada RS.Bhayangkara kota Palu tahun 2017 didapatkan nilai 60,60\% yaitu dikategorikan berkualitas sedang. Hasil penelitian ini sama dengan hasil penelitian Kubri A pada RSUD kepulauan meranti dan Jefryanto pada RSUD mandau yang berkualitas sedang, hasil nilai yang didapatkan secara berurutan adalah $50 \%$ dan $72,64 \%$.,12 


\section{SIMPULAN DAN SARAN SIMPULAN}

Dari hasil penelitian ini terlihat bahwa hasil laporan kualitas VeR perlukaan korban hidup belum sesuai harapan atau masih dapat dikatakan dibawah standar. Secara keseluruhan rerata nilai yang didapatkan masih berkualitas sedang. Hal ini dapat disebabkan tidak adanya format yang memenuhi standar penulisan VeR perlukaan atau ketidaktahuan sebagian dokter akan unsur-unsur yang harus dinilai pada $\mathrm{VeR} .{ }^{9}$ fungsi $\mathrm{VeR}$ sebagai alat bukti dalam membantu hakim dalam menjatuhkan pidana dalam proses peradilan dapat berkurang bila kualitas VeR yang dibuat dokter rendah. ${ }^{6}$

\section{SARAN}

Khusus bagi dokter umum yang berada di Instalasi Gawat Darurat (IGD) dan RS Bhayangkara kota Palu secara umum untuk :

1. Dapat membuat prosedur tetap mengenai pembuatan Visum et Repertum terutama Visum et Repertum perlukaan yang memenuhi standar yang baik bagi dokter umum.

2. Sosialisasi secara berkala kepada dokter umum mengenai tata cara penulisan Visum et Repertum

3. Dalam membuat Visum et Repertum bagian pendahuluan secara lengkap terutama variabel tempat pemeriksaan, waktu pemeriksaan, dan data peminta pemeriksaan.

4. Dalam membuat Visum et Repertum pada bagian pemberitaan secara lengkap terutama variabel anamnesis dan pengobatan serta perawatan.

5. Pembuatan Visum et Repertum agar pada bagian kesimpulan secara lengkap terutama variabel kualifikasi luka.

\section{DAFTAR PUSTAKA}

1. Idries AM, Pedoman Ilmu Kedokteran Forensik. Tangerang Selatan: Binarupa Aksara Publisher.

2. Asmarawati T. Hukum dan Psikiatri: Deepublish. 2015

3. Afandi D. Visum et Repertum Tatalaksana Dan Pembuatan. 2nd ed. Riau: Fakultas Kedokteran Universitas Riau. 2017
4. Afandi D. Visum et Repertum Perlukaan: Aspek Medikolegal dan Penentuan Derajat Luka. 2010 april 4 [cited 2017 october 10]

5. Herkutanto. Peningkatan Kualitas Pembuatan Visum Et Repertum (VER) Kecederaan Di Rumah Sakit Melalui Pelatihan Dokter Unit Gawat Darurat (UGD). 2005 september [cited 2017 october 10]

6. Herkutanto, Pusponegoro AD, Sudarmo S. Aplikasi Trauma-Related Injury Severity Score (TRISS) untuk penetapan derajat luka dalam kontek medikolegal. J I Bedah Indonesia. 2005;33(2):37-43.

7. Herkutanto. Kualitas visum et repertum perlukaan di Jakarta dan faktor yang mempengaruhinya. Jakarta: Majalah KedokteranIndonesia. 2004;54(9):355-60.

8. Soularto DS. Analisis Kualitas Visum et Repertum Beberapa Dokter Spesialis pada Korban Kekerasan Seksual di RS PKU Muhammadiyah Yogyakarta. 2009 april [cited 2017 october 15]

9. Kubri A, Afandi D, Mursali LB. Kualitas Visum Et Repertum Perlukaan Di RSUD Kepulauan Meranti Periode 1 Januari 2010 - 31 Desember 2013. 2015 februari [cited 2017 october 10]

10. Pratiwi WS, Afandi D, Masdar $\mathrm{H}$. Gambaran Visum Et Repertum Perlukaan Di Rumah Sakit Umum Daerah Kuantan Singingi Periode 1 Januari 2009 - 31 Desember 2013. 2015 februari [cited 2017 october 11]

11. Lestari RA, Afandi D, Mursali LB. Kualitas Visum Et Repertum Perlukaan Di Rumah Sakit Umum Daerah Bengkalis Periode 1 Januari 2009-31 Desember 2013. 2015 oktober [cited 2017 october 11]

12. Jefryanto, Afandi D, Riswandi. Kualitas Visum Et Repertum Perlukaan Di Rumah Sakit Umum Daerah Mandau Periode 1 Juni 2011- 30 Juni 2013. 2015 oktober [cited 2017 october 11]

13. Ramadhan FT, Afandi D, Mursali LB. Kualitas Visum Et Repertum Perlukaan Di RSUD DR.RM.Pratomo Bagan Siapi-Api Periode 1 Januari 2009 - 31 Desember 2013. 2015 februari [cited 2017 october 11]

14. Simangunsong IR, Afandi D, Burhanuddin L. Kualitas Visum Et Repertum Perlukaan 
MEDIKA ALKHAIRAAT : JURNAL PENELITIAN KEDOKTERAN DAN KESEHATAN 3(3):117-123

e-ISSN: 2656-7822, p-ISSN: 2657-179X

Di Rumah Sakit Umum Daerah Siak

Periode 1 Januari 2009-31 Desember 2013.

2015 Oktober [cited 2017 october 11] 